\title{
Frequency of diabetic retinopathy in Mosul
}

\author{
Amer Y. Rajab \\ Department of Surgery. College of Medicine, University of Mosul.
}

(Ann. Coll. Med. Mosul 2008; 34(2):129-134).

Received: $2^{\text {nd }}$ Oct 2007; Accepted: $21^{\text {st }}$ May 2008.

\begin{abstract}
Aim: To study the frequency of diabetic retinopathy in a population of patients and to evaluate the medical risk factors underlying its development.

Methods: A case series study conducted at the out patient clinic of Al Jamhoury teaching hospital and at a private clinic in Mosul, during the period from Jan. 2005 to Dec. 2006. One hundred and seventy patients with diabetes were randomly selected by ophthalmologist. They were referred by physicians after they did diabetic profile by history and medical examination. The WHO definition of diabetic retinopathy was recommended, several risk factors were searched for during the evaluation of the patients.

Results: the prevalence of diabetic retinopathy was $32.35 \%, 20 \%$ in type I diabetes, and $80 \%$ in type 2 diabetes and surprisingly both of which had equal rate of retinopathy in this population. $80 \%$ did not know about the need of regular dilated fundus examination. The mean age was 50 years old ranging from 25-67 years, with 65\% between the ages of 50-65 years old and the standard deviation was $( \pm 10.95)$. Male to female ratio was $1: 1.5$ with equal rates of retinopathy $(29.4 \%$ vs $34.3 \%)$. The retinopathy rate was highest in the age group $50-59$ years (37\%). The rate of non-proliferative diabetic retinopathy, proliferative diabetic retinopathy and diabetic maculopathy were 18.8\%, 12.9\% and $14.5 \%$ respectively

The rate was higher among subjects with longer duration of diabetes, higher fasting plasma glucose, and cases with hypertension.

Conclusion: Public education is essential about the need for routine and regular dilated fundus examination for diabetic patients in addition to glycemic control; lowering diastolic blood pressure (in hypertensive patients) may be effective in lowering the incidence of retinopathy in compromised patients.
\end{abstract}

الهُف: معرفة العوامل المؤثرة أو العوامل الخطورة لاعتلال الثبكية لمرضى داء السكر في منطقة الموصل. التصميم : در اسة سلسلة الحالات.

المكان: العيادة الخارجية لمستشفى الجمهوري التعليمي و العيادة الخاصة.

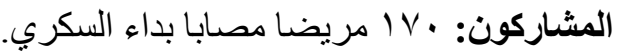

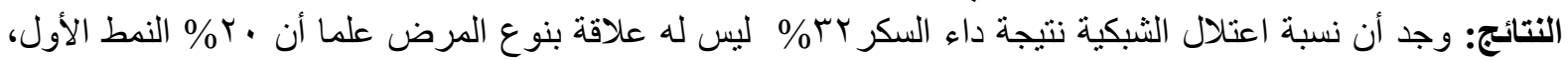

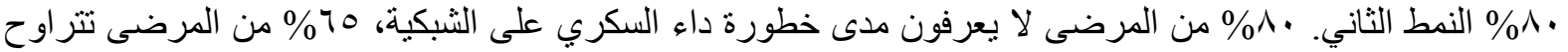

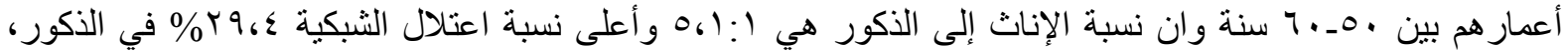

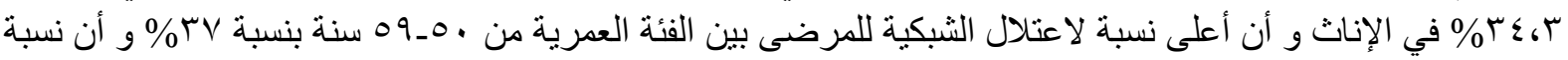

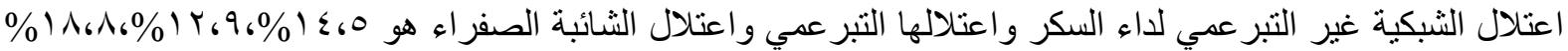
بالتتابع. إن اعتلال الثبكية يتناسب طرديا وفترة المرض و عدم السيطرة على داء السكر(ارتفاع السكر في الدم)و ارتفاع ضغط الدم. 
The world health organization (WHO) estimated that there are currently about 150 million people with diabetes and this number will be doubled by the year 2025 . Retinopathy is the most common complication in diabetic especially diabetes mellitus (type 1). Diabetes retinopathy (DR) is a leading cause of visual disability in the industrialized countries $^{(1)}$. The causes of such morphological changes in diabetes could be grouped into three categories: biochemical, hemodynamic and humoral ${ }^{(2)}$. Of these, the biochemical changes related to prolonged hyperglycemic state (as evidenced by increased level of glycosylated hemoglobin) are important, and many studies confirmed the association between prolonged hyperglycemia and diabetic retinopathy ${ }^{(3-5)}$.

Other factors which were also implicated in the occurrence of the DR include, the duration of the diabetes ${ }^{(6)}$, types of the treatment ${ }^{(7)}$, associated hypertension ${ }^{(8,10)}$, proteinuria $^{(11)}$, serum creatinine level ${ }^{(12)}$, serum cholesterol and triglycerides level ${ }^{(13,14)}$. Changes in lifestyle have also increased the risk of diabetes in many developing countries ${ }^{(15)}$ and it is important that organized efforts are undertaken to address eye complications of diabetes.

Around $20 \%$ of people with diabetes projected to develop retinopathy ${ }^{(16)}$. A number of studies have shown marked difference in the prevalence of DR whether in type ${ }^{(17-19)}$ or in the type 2 diabetes in different countries; however, reliable information on the magnitude and determinants of ocular manifestations of diabetes in many countries including Iraq is lacking.

Iraqi population (including Mosul population) had undergone rapid socioeconomic development and improvement in their life style in the past three decades. There has been marked decline in the communicable diseases and nutritional disorders. Noncommunicable diseases like diabetes have increased owing to increase in the incidence of obesity, sedentary life style, smoking, consanguinity, stress and other factors. Diabetes has become a major emerging clinical and public health problem in Iraq.
The study of incidence and progression of DR and associated risk factors are important in the prevention of the development and progression of the problem ${ }^{(15)}$. The aim of the study is to demonstrate the frequency of DR in a randomly selected population of patients to evaluate the medical risk factors underlying its development. The specific objective is to distribute the study samples according to their ages and sexes, and to grade retinopathology among the studied sample.

\section{Patients and method:}

This is a case series study including one hundred and seventy patients with the clinical diagnosis of diabetes. All patients have ocular media allowing detailed and accurate fundus examinations. Patients with media opacities were excluded from this study.

Those diagnosed and referred by many physicians to the ophthalmology unit for the examination of their ocular changes, during the period from Jan. 2005 to Dec. 2006 were included. The physician did the diabetic profile of the patients while the ophthalmologist reported the ocular profile, reporting any retinal changes as seen in the table (1) ${ }^{(20-21)}$. Patients' knowledge of ocular risks of diabetes and the need for routine examination was evaluated using medical history as to how far patients know the risk of affection of their eyes by diabetes. Several factors were considered in evaluation of the patients in order to identify the occurrence of the retinopathy. The referring physicians noted details including patient's age, sex, duration of diabetes, blood sugar profile, HbAlc levels, associated systemic complications, (nephropathies, neuropathies hypertension, hyperlipidemia, coronary artery diseases etc.) All subjects were sent to the ophthalmologist for ocular assessments.

Visions examined for each eye separately using Snellen distance vision chart at six meters. The anterior segments were examined by slit lamp and the pupils dilated by using tropicamide $1 \%$ and phenylephrine $10 \%$. The retinal examination (+90D lens and indirect ophthalmoscope) was carried out after pupillary dilatation and different findings carefully recorded. Patients were classified 
according to the grading in the worse eye. Table (1) shows a simplified grading scale utilized in our study. The collected data were analyzed by Z-test. Patients with photocoagulation scar were assigned to the proliferative group; any patients with corneal opacity or lenticular opacities, which precluded proper fundus examination, were excluded from the study. In the presence of PDR and /or clinically significant diabetic maculopathy, laser therapy was proposed. Patients with advanced diabetic eye complications that necessitate sophisticated surgical interventions were referred to an advanced center outside Iraq.

\section{Results:}

The prevalence of DR was $32 \% \quad$ (55 patients). Type 1 diabetes was found in $20 \%$, while type 2 was found in $80 \%$. Mean age was 50 years ranging from 25-67 years, and 65\% of the patients were between 50-65 years and the standard deviation was $( \pm 10.95)$. The retinopathy rate was highest among the age group of 50-59 years, which was (37\%) and male to female ratio was $1: 1.5$, with different rate of retinopathy $(29.4 \%$ vs $34.3 \%)$ as shown in table (2). The rate of non-proliferative DR, PDR, and diabetic maculopathies were $(18.8 \%, 12.9 \%$ and $14.5 \%)$ respectively as shown in table (3).

The risk of retinopathies and its severity increased with increase in the duration of diabetes as shown in table (4). The rate was higher among subjects with longer duration of diabetes, highest fasting plasma glucose and in cases with hypertension. In our study $80 \%$ of the patients did not know about the ocular risks of diabetes and the need for routine dilated eye examination.

Laser treatment was performed on patients with CSME and patients with PDR. Six patients with PDR referred to the ophthalmic surgery out side Iraq.

Table (1): The grading scale

INTERNATIONAL CLINICAL DIABETEIC RETINOPATHY DISEASES SEVERITY SCALE ${ }^{(20,21)}$.

No apparent DR............................No abnormalities.

Mild non- proliferative DR.................Micro aneurysm only.

Moderate non- proliferative DR............More than mild ,but less than severe.

Severe non- proliferative DR Any of the following;

A: 20 or more intra-retinal hemorrhage in four quadrants.

B: Definitous beading in 2 or more quadrants.

C: Prominent IRMA in one or more quadrants and no neovascularization.

Proliferative DR one or more of the following:

A: definite neovascularization.

B: Pre- retinal or vitreous hemorrhage.

IRMA: intra-retinal micro vascular abnormalities.

Table (2): the age distribution of patients

\begin{tabular}{|c|c|c|c|c||}
\hline $\begin{array}{c}\text { Age groups (in } \\
\text { years) }\end{array}$ & $\begin{array}{c}\text { Male } \\
\text { No. \& \% }\end{array}$ & $\begin{array}{c}\text { Female } \\
\text { No. \& \% }\end{array}$ & Total & P-value \\
\hline \hline$<30$ & $4(2.35 \%)$ & $4(2.35 \%)$ & $8(4.7 \%)$ & n.s \\
\hline $30-44$ & $20(11.8 \%)$ & $27(15.8 \%)$ & $47(27.6 \%)$ & n.s \\
\hline $45-60$ & $29(17.05 \%)$ & $53(31.15 \%)$ & $82(48.2 \%)$ & n.s \\
\hline$>60$ & $15(8.8 \%)$ & $18(10.61 \%)$ & $33(19.4 \%)$ & n.s \\
\hline Total & $68(40 \%)$ & $102(60 \%)$ & $170(100 \%)$ & $<0.05$ j.s \\
\hline
\end{tabular}


Table (3): the grade of retinopathy among the studied groups.

\begin{tabular}{|c|c|c||}
\hline Severity of diabetic retinopathy & No. \& \% & p-value \\
\hline \hline No DR & $115(67.6 \%)$ & $<0.001$ (v.h.s) \\
\hline NPDR & $33(19.4 \%)$ & $<0.001$ (v.h.s) \\
\hline PDR & $22(12.9 \%)$ & $<0.001$ (v.h.s) \\
\hline CSME & $25(14.7 \%)$ & $<0.001$ (v.h.s) \\
\hline
\end{tabular}

v.h.s= very highly significant; No $\mathrm{DR}=$ free from diabetic retinopathy; $\mathrm{NPDR}=$ non proliferative diabetic retinopathy; $\mathrm{PDR}=$ proliferative diabetic retinopathy; $\mathrm{CSME}=$ clinically significant macular edema

Table (4): the distribution of retinopathy grades with the duration.

\begin{tabular}{|c|c|c|c|c|c||}
\hline Durations & $<1$ year & $1-5$ years & $5-15$ years & $>15$ years & Total \\
\hline \hline FREE & $13(92.9 \%$ & $58(82.9 \%)$ & $35(53.8 \%)$ & $9(45 \%)$ & 115 \\
\hline NPDR & $1(7.1)$ & $8(11.4 \%)$ & $18(27.7 \%)$ & $6(30 \%)$ & 33 \\
\hline CSME & $1(7.6 \%)$ & $3(5.2 \%)$ & $21(60 \%)$ & ---- & $-\cdots$ \\
\hline PDR & ---- & $5(5.7 \%)$ & $12(18.5 \%)$ & $5(25 \%)$ & 22 \\
\hline Total & 14 & 71 & 65 & 20 & 170 \\
\hline
\end{tabular}

\section{Discussion:}

In order to reduce the visual disabilities and improve the quality of life of people with diabetes, information on DR is crucial. Since the study sample was randomly selected from cases (both newly discovered and old one) attending to other hospital and private clinics, it may roughly represents the prevalence rate of DR in Mosul province. People with diabetes and an opaque media in both eyes, because of either trachomatous, non-trachomatous corneal opacities or cataract are not more or less likely to have DR; hence excluding these patients should not have introduced systemic bias. The prevalence of DR in our study sample was $32 \%$. Global projections suggest that $20 \%$ of diabetic cases will develop $\mathrm{DR}^{(22)}$. It is reported as low as $6.7 \%$ in South India ${ }^{(23)}$, $11.6 \%$ in Saudi Arabia $^{(24)}$ and $6.9 \%$ in China ${ }^{(25)}$. Studies in Ethiopia, France and Japan demonstrated higher rates ${ }^{(26-28)}$.

Our higher prevalence could be explained by the lack of proper screening programs in our population and bad control of diabetes, stress and lack of health coverage.

In Mosul, women had significantly higher rate of DR than men, as it seems that females may take care about their general health more than males, which is similar to a study in Sweden where women had a higher rate than men $^{(29)}$. Other studies have suggested insignificant differences in DR by $\operatorname{sex}^{(30-31)}$. The retinopathies rate increased with age until the age of 70 years; however, the small number of people with diabetes in this age group limits our ability to interpret the finding. Furthermore, the large number of cases with opaque media in this age group (due to cataract or corneal opacities) rendered examination impossible. The positive association between DR and duration of diabetes is noted in the literature. The retinopathy rate in Southern India was 7\% in individuals with short duration of diabetes (less than 10 years), 26\% in those with 10-14 years duration and $63 \%$ in those with 15 years and more duration of diabetes ${ }^{(32)}$. Similar observations were found in our study.

The diabetes maculopathies rate was $14.7 \%$ in our study. The rate of maculopathy was $6.4 \%$ in India $^{(33)}$, and $8 \%$ in Japan ${ }^{(34)}$. In view of such high rate of macular involvement, resources for laser therapy should be planned with special focus on care of diabetic maculopathies. 
The prevalence of DR was higher in those with hypertension, which is similar to other studies $^{(35)}$. The use of laser treatment is very low compared to the actual need. This could increase the backlog of untreated retinopathy cases resulting in more visually disabled people with diabetes. The underlying causes of low use (lack of awareness, lack of access, or lack of resources) should be addressed through a comprehensive approach to improve screening and management of DR.

Our study also revealed the low level of patient's knowledge about the ocular hazard of diabetes and the need for routine dilated eye examination. Patients seen were directed by physicians to see an ophthalmologist as part of the study involved. Screening programs have to be outlined and highlighted by national health authorities.

Recommendation:

Public education is essential about the need for routine and regular dilated fundus examination for diabetic patients. In addition to good glycemic control, lowering diastolic blood pressure (in hypertensive patients) may be effective in lowering the incidence of DR in compromised patients.

\section{References:}

1. Resnikoff S, Pararajasegaram R. Blindness prevention programmes past, present and future Bull World Health Organ 2001: 79:222-6.

2. Merimee TJ. Diabetic retinopathy: a synthesis of perspectives. N Eng J Med 1990;322:979-983

3. Heriot $\mathrm{WJ}$, Borger JP, Zimmet $\mathrm{P}$, et al . Diabetic retinopathy in a natural population. Aust J Ophthalmol 1983;11:175-179

4. Agardh E, Agardh EC, Torffvit O . A 5-year follow-up study on the incidence of retinopathy in type 1 diabetes mellitus in relation to medical risk indicators. $J$ Intern Med 1994; 235:351-358.

5. The Diabetes Control and Complications Trial. The effect of intensive diabetes treatment on the progression of diabetic retinopathy in insulin dependent diabetes mellitus. Arch Ophthalmol 1995;113:36-51.

6. Erasmus RT, Alanamu RA, Bojuwoye B, et al . Diabetic retinopathy in Nigerians: relation to duration of diabetes, type of treatment and degree of control. East Africa Med J 1989; 66:248-254.

7. Klein R, Klein BEK, Moss SE, et al. The Wisconsin epidemiologic study of diabetic retinopathy. III. Prevalence and risk of diabetic retinopathy when age at diagnosis is thirty years or more. Arch Ophthalmology 1984; 102:527-532.

8. Janka HU, Warram JH, Rand LI, et al . Risk factors for progression of diabetic retinopathy in long standing IDDM. Diabetes 1989;38:460-464

9. Klein R, Klein BEK, Moss SE, et al. Is blood pressure a predictor of the incidence or progression of diabetic retinopathy? Arch Intern Med 1989;149:2427-2432.

10.Orchard TJ. From diagnosis and classification to complications and therapy. Diabetes Care 1994; 17:329-338.

11.Klein R, Moss SE, Klein BEK. Is gross proteinuria a risk factor for the incidence of proliferative diabetic retinopathy? Ophthalmology 1993;100:1140-1146

12. Engelmann R, Blood worth JMB, Nelson S. Relationship of micro vascular disease in diabetes to metabolic control. Diabetes 1977;26:760-769.

13. The EURODIAB IDDM Complications Study. Retinopathy and vision loss on insulindependent diabetes in Europe. Ophthalmology 1997;104:252-260.

14. Muh SC, Chie SK, Chin JC, et al. Prevalence and risk factors of diabetic retinopathy among non-insulin dependent diabetic subjects. Am J Ophthalmology 1992;114:723-730

15.World Health Organization. Definitions, diagnosis and classification of diabetes mellitus and its complications. Report of a WHO consultation. WHO/NCD/NCS/99.2. Geneva: WHO

16. Miller SJH . Parson's diseases of the eye. 18th ed. Edinburgh: Churchill Livingston, 238-9

17. Marshall G, Garg SK, Jackson WE, et al. Factors influencing the onset and progression of diabetic retinopathy in subjects with insulin-dependent diabetes mellitus. Ophthalmology 1993;100:11331139. 
18.Segato T, Midena E, Grigoletto F, et al. The epidemiology and prevalence of diabetic retinopathy in the Veneto region of north east Italy. Veneto Group for Diabetic Retinopathy. Diabet Med 1991; 8:511-516.

19.Agardh E, Torffvit O, Agardh CD . The prevalence of retinopathy and associated medical risk factors in type I (insulindependent) diabetes mellitus. J Intern Med 1989;226:47-52

20.Diabetic Retinopathy Study Research Group (DRSRG). A modification of the Airlie House classification of diabetic retinopathy. Diabetic Retinopathy Study Report No 7 Invest Ophthalmol Vis Sci 1981; 21:210-26.

21.Early Treatment Diabetic Retinopathy Research Group (ETDRRG). Grading diabetic retinopathy from stereoscopic color fundus photographs; an extension of the modified Airlie House classification. Early Treatment Diabetic Retinopathy Study Report No.10. Ophthalmology 1991; 98 (Suppl) : 786-806.

22.El Haddad OA, Saad MK. Prevalence and risk factors for diabetic retinopathy among Omani diabetics. $\mathrm{Br} \quad \mathrm{J}$ Ophthalmol 1998;82:901-6

23.Ramachandran A, Snehalatha C, Vijay V, et al. Diabetic retinopathy at the time of diagnosis of NIDDM in south Indian subjects. Diabetes Res Clin Pract 1996;32:111-

24.Al-Khaldi YM , Khan MY, Khairallah SH. Audit of referral of diabetic patients. Saudi Med J 2002;23:177-81.

25. He S, Guo Y, Li Z. Epidemiologic study of diabetic retinopathy in Capital Steel Company Chung Hua Yen Ko Tsa Chih 1997;33:381-3.

26. Seyoum B, Mengistu Z, Berhanu P, et al. Retinopathy in patients of Tikur Anbessa
Hospital diabetic clinic. Ethiop Med J 2001;39:123-31

27.Donnio-Cordoba A, Richer R, Spinelli F, et al. Diabetic retinopathy in Martinique: results of a cross-sectional survey based on 771 patients J Fr Ophtalmol 2001; 24:603-9.

28. Funatsu $\mathrm{H}$, Suto $\mathrm{C}$, Hori $\mathrm{S}$, et al. Prevalence of diabetic ocular complications and systemic factors. Nippon Ganka Gakkai Zasshi 1993; 97:947-54.

29.Jerneld B, Algvere P. Relationship of duration and onset of diabetes to prevalence of diabetic retinopathy. Am J Ophthalmol 1986;102:431-7.

30.Segal $P$, Treister $G$, Yalon $M$, et al. The prevalence of diabetic retinopathy: effect of sex, age, duration of disease and mode of therapy. Diabetes Care 1983;6:149-51.

31.Araki $\mathrm{A}$, Ito $\mathrm{H}$, Hattori $\mathrm{A}$, et al. Risk factors for development of retinopathy in elderly Japanese patients with diabetes mellitus. Diabetes Care 1993;16:1184-6

32.Bresnick GH . Diabetic retinopathy. In: Principals and practice of ophthalmology. 1st ed. Philadelphia: WB Saunders, 1987; Vol II, chapter 19:1205-76

33. Rema M, Ponnaiya M, Mohan V. Prevalence of retinopathy in non insulin dependent diabetes mellitus at a diabetes centre in southern India. Diabetes Res Clin Pract 1996; 34:29-36.

34. Matsuhashi $\mathrm{H}$, Tamura $\mathrm{M}$, Kudoh $\mathrm{M}$, et al. Epidemiologic study of diabetic retinopathy in nine hospitals in the Aomori area. Nippon Ganka Gakkai Zasshi 2001; 105:760-5.

35.Garancini $\mathrm{P}$, Micossi $\mathrm{P}$, Valsania $\mathrm{P}$, et al. Prevalence of retinopathy in diabetic subjects from out-patient clinics in Lombardy ( Italy), and associated risk factors. A multicoated epidemiologic study. Diabetes Res Clin Pract 1989;6:129-38. 